\title{
INCLUSÃO DE UMA ALUNA COM DEFICIÊNCIA NO CONTEXTO DE UM CURSO DE ENSINO SUPERIOR DA ÁREA DA SAÚDE
}

\author{
INCLUSION OF A STUDENT IN A SUPERIOR HEALTH DEGREE
}

\author{
Rafael da Silva Passos, Emanuele da Silva Passos
}

Universidade Estadual do Sudoeste da Bahia - UESB

\begin{abstract}
Students with Disabilities (SwD) face many obstacles in the education environment, but several public policies of inclusive education are to allow the entry of the same in this environment. The legislation in the area exists to allow the SWD access to common educational environments, ensure special care according to the peculiar characteristics of the condition of each student, setting requirements for accessibility at the college and ensure the financing of educational apparatus. The aim of this study was to report the living experience with a SWD in a physiotherapy graduation at a University in northeastern Brazil. During graduation, the barriers imposed by itself, considering limitation of physical space, difficulties in transmitting the content in various disciplines, the support of the University took place, especially for the performance of a inclusion center, who worked on educational, material and human support, providing, in the best possible way, the necessary materials. However, it was possible to notice a difficulty, especially from teachers, to work with an SwD, thinking of the inclusion point of view. The inclusion of SWD in the college environment is possible, however, it is essential to happen cooperation between the political, educational sectors and manager, to provide the best possible conditions for the SWD be included in the college.
\end{abstract}

Key words: Inclusive Education; Health; Physiotherapy

\section{Resumo}

Os Alunos com Deficiência (AcD) enfrentam diversos obstáculos no ensino superior, mas diversas políticas públicas de educação inclusiva existem no sentido de permitir a entrada do mesmo nesse ambiente. A legislação na área existe no sentido de permitir o acesso do AcD aos ambientes comuns de ensino, assegurar $o$ atendimento especial de acordo às características peculiares da condição de cada aluno, estabelecer os requisitos para a acessibilidade no ambiente do nível superior e garantir o financiamento desse aparato educacional. $O$ objetivo desse estudo foi relatar a experiência de convivência com uma AcD em um curso de Fisioterapia em uma Universidade no Nordeste brasileiro. Ao longo da graduação, com as barreiras impostas pela mesma, considerando limitação de espaço físico, dificuldades em transmitir o conteúdo nas mais diversas disciplinas, o apoio da Universidade aconteceu, sobretudo pela atuação de um núcleo de inclusão, que trabalhou no apoio didático, material e humano, fornecendo, da melhor maneira possivel, os materiais necessários. No entanto, foi possível perceber uma dificuldade, sobretudo docente, de trabalhar com a $A c D$, pensando do ponto de vista da inclusão. A inclusão do $A c D$ na universidade é possível, no entanto, é indispensável que aconteça uma cooperação entre os setores político, educacional $e$ gestor, no sentido de prover as melhores condições possíveis para que o AcD seja incluído na educação de nível superior.

Palavras chave: Educação inclusiva; saúde; fisioterapia 
Introdução

Diversos são os obstáculos existentes para a inclusão do Aluno com Deficiência (AcD) no ambiente da Educação. Apesar de todas essas dificuldades, é imprescindível que se discuta que os AcD têm o direito de participar do processo educacional, e não apenas da educação básica, mas também do Ensino Superior.

As Políticas Públicas de Educação Inclusiva imputadas no Ensino Superior ganharam destaque por garantir 0 acesso do $A c D$ à educação básica, sendo dignos de nota os esforços legislativos contidos: no art. 208, III da CF/ $1988^{1}$ e o art. 58 do Cap. V da Lei de Diretrizes e Bases da Educação Nacional (Lei no 9.394/96) ${ }^{2}$, que normatizam o direito à efetiva participação dos alunos com deficiência na escola comum; bem como o atendimento especial segundo as diferenças $e$ as peculiaridades segundo a resolução CNE/CEB no 2, de 11 de setembro de 2001 (Diretrizes Nacionais para a Educação Especial na Educação Básica) ${ }^{3}$.

Considerando a legislação do ponto de vista para a inclusão de estudantes com deficiência no Ensino Superior, podemos destacar: o Aviso Circular n²77/1996 do MEC, que propõe a adequação pelas Universidades do processo seletivo de estudantes com necessidades especiais no Ensino Superior, sobretudo no concurso de vestibular, e recomenda a promoção da "flexibilização dos serviços educacionais e da infraestrutura, bem como a capacitação de recursos humanos" ${ }^{2}$, de forma a assegurar a permanência bem sucedida de estudantes "portadores de necessidades especiais"; a Portaria no 1.679/1999, que discorre sobre os requisitos de acessibilidade para pessoas com deficiências com vistas a instruir processos de autorização e de reconhecimento de cursos e de credenciamento de instituições; a Portaria $\mathrm{n}$ 응 $3.284 / 2003$, que substituiu a anterior, sendo ainda mais específica na enumeração das condições de acessibilidade que devem ser implementadas pelas IES; e o Decreto $n^{\circ} 5.296 / 2004$, conhecida como Lei de Acessibilidade, que regulamenta os requisitos importantes para a acessibilidade no que tange à inclusão educacional, orientando as técnicas importantes para o cumprimento da Portaria de 2003, estabelecendo a importância de prover adequadas condições de acesso e utilização de todos os ambientes ou compartimentos para pessoas com deficiência ou mobilidade reduzida, considerando todos os níveis, etapas ou modalidades de estabelecimentos de ensino, sejam elas públicas ou privadas. Além disso, é importante que se permita que haja o suporte técnico necessário para permitir o acesso às atividades escolares e administrativas em iguais condições com as demais pessoas ${ }^{4}$.

O Decreto $n^{\circ} 7611 / 2011$ institui a política pública de financiamento no âmbito do Fundo de Manutenção e Desenvolvimento da Educação Básica e de Valorização dos Profissionais da Educação - FUNDEB, estabelecendo o duplo cômputo das matrículas dos estudantes com deficiência, transtornos globais do desenvolvimento e altas habilidades/superdotação. Além disso, esse decreto define o atendimento educacional especializado complementar ou suplementar à escolarização e os demais serviços da educação especial, dentre outras medidas para a inclusão escolar 5

A partir dessas legislações, podemos notar que existe um movimento para a inclusão do $A c D$ no ensino superior/universidade, permitindo que existam diversos direitos assegurados pela legislação. A Política Nacional de Educação Especial de 2008 resume bem que é importante, não apenas que os alunos tenham acesso à educação, mas que se permita a permanência e a organização de recursos e serviços, em prol dos processos seletivos e todas as atividades que envolvam ensino, pesquisa e extensão ${ }^{6}$.

Partindo dessas informações expostas, surge o questionamento sobre a efetividade desse aparato burocrático no ambiente do nível superior. Diante disso, esse trabalho visa descrever as experiências de convivência com uma ACD visual no Curso de Bacharelado em Fisioterapia em uma Universidade no nordeste do Brasil, buscando dividir os desafios enfrentados pela $A c D$ ao longo da graduação, bem como as dificuldades dos docentes e de que forma a Universidade proporcionou suporte para o andamento das atividades.

\section{Relato de experiência}

A Fisioterapia é a ciência que estuda, diagnostica, previne e recupera pacientes com distúrbios cinéticos funcionais intercorrentes em órgãos e sistemas do corpo humano, trabalhando com doenças geradas por alterações genéticas, traumas e enfermidades adquiridas. Dentre os principais objetivos, podemos apontar principalmente a preservação, manutenção, desenvolvimento ou reabilitação da integridade de órgãos, sistemas ou funções, e os conhecimentos e recursos próprios se agrupam 
para formular o melhor processo terapêutico possível para melhora da qualidade de vida e funcionalidade dos pacientes.

Por conta disso, a Fisioterapia necessita de conhecimentos em diversas áreas, envolvendo conhecimentos biológicos (anatomia, fisiologia, bioquímica, patologia, cinesiologia e biomecânica), físicos (eletrotermofototerapia), disciplinas comportamentais e sociais (sociologia, psicologia, antropologia), diversas disciplinas específicas de técnicas fisioterapêuticas, o cumprimento dos estágios obrigatórios, e a disciplina de Trabalho de Conclusão de Curso.

Para as disciplinas de conhecimentos biológicos e sociais, dispostas logo nos primeiros semestres da graduação, a AcD (daqui em diante nominada Cecília - nome fictício para preservar a identidade) precisou contornar o fato de que, a maior parte dessas disciplinas apresentam conteúdos basicamente visuais. Nesse momento, a atuação do Núcleo de Ações Inclusivas para Pessoas com Deficiência da Universidade acabou sendo importante por diferentes aspectos: considerando o apoio à Cecília, o mesmo se deu pela transcrição de materiais didáticos para documentos legíveis ao software específico de leitura, pela confecção de recursos didáticos que permitissem que, através do tato, a mesma pudesse ter a informação necessária, assim como realizando o atendimento especializado educacional; e para os professores, uma preparação básica com informações sobre como adaptar as aulas para melhor atender às necessidades de Cecília.

Considerando as disciplinas de conhecimentos físicos e de técnicas, houve uma necessidade dos professores de se prepararem ainda melhor para atender às demandas de Cecília. O principal desafio nesses conjuntos de disciplinas consistia no fato dessas disciplinas contarem com grandes cargas horárias descritivas de atos motores e técnicas. Nessas disciplinas, Cecília acabava sendo a modelo para a realização das condutas, de modo a melhor compreender como as mesmas se realizam, a partir da demonstração física e descrição falada. Em diversos momentos, os demais colegas da classe auxiliavam na descrição de técnicas e apresentações, bem como oferecendo outra visão no processo de aprendizagem.

Ao longo dessas e das demais disciplinas, Cecília desempenhava suas avaliações ou de forma oral ou pelo computador, onde o professor disponibilizava o arquivo da prova para a aluna e um maior tempo para a realização da mesma, tal como está determinado no Estatuto da Pessoa com Deficiência (Lei 13.146/2015). ${ }^{7}$

No momento da apresentação do Trabalho de Conclusão de Curso, Cecília contou com o apoio de uma ledora, pelo fato de seu trabalho ter apresentado extensas quantidades de textos corridos.

Para os estágios obrigatórios, a Universidade contratou uma fisioterapeuta para "emprestar os olhos" para Cecília, permitindo que a fisioterapeuta realizasse a observação do paciente e das informações visuais presentes durante os atendimentos, pois, em alguns setores nos quais eram realizados os estágios, não existia uma adaptação que permitisse a autonomia para Cecília, no que diz respeito à obtenção de parâmetros clínicos. Desse modo, o papel dessa fisioterapeuta era de prover as informações para tomadas de decisões clínicas, jamais visando qualquer suporte no sentido de facilitar os atendimentos.

Também foi nos estágios que, por conta do caráter do curso, de ter muito contato com pacientes portadores das mais diversas deficiências, destacando-se o contato com deficientes físicos, visuais e intelectuais, o que contribuiu ainda mais para o enriquecimento de suas experiências e conhecimentos, bem como para a motivação dos pacientes, sendo que muitas passaram a vê-la como um exemplo e inspiração a ser seguida. De diversas formas, Cecília pôde realizar uma troca de experiências com essas pessoas, principalmente mostrando as possibilidades de inclusão na sociedade, para muito além de qualquer deficiência.

\section{Discussão}

Dentro do que foi aqui discutido, devemos levantar algumas questões acerca da proposta de inclusão que existe dentro de nossas Academias. Dentre as principais dificuldades enfrentadas para a inclusão dos AcD, podemos destacar a falta de formação docente, falta de eficácia das ações de implantação da inclusão nas instituições de ensino e também a inadequação das práticas pedagógicas nas universidades que se propõem à inclusão. A partir de tais desafios, podemos sugerir, a partir daquilo que foi aqui discutido, algumas ações a serem tomadas.

No que tange a formação dos professores, a existência de uma inadequação entre o currículo institucional e a realidade a ser enfrentada, torna-se barreira na relação entre docentes e pelos discentes $A c D$. Entender que os $A c D$ não precisam de facilitação e sim de adaptação dos 
conteúdos de cada disciplina para permitir a melhor compreensão da realidade que é apresentada. Dessa forma a adequação entre a falha do currículo e a necessidade enfrentada pelo discente $A c D$ deve impulsionar os professores à buscar os conhecimentos e a formação apropriada para lidar com os AcD, e as necessidades especificas dos mesmos no processo de aprendizagem. Essas adaptações perpassam desde uma simples alteração de linguagem durante as aulas, até a construção de modelos e maquetes que permitam a visualização necessária para o entendimento ${ }^{8}$.

Considerando a falta de eficácia das ações de implantação da inclusão, pode-se atuar a partir de duas vertentes: despertar a vontade política de governantes e gestores para alçar a inclusão nas escolas e estimular a participação de especialistas da área da educação inclusiva na elaboração de tais políticas, buscando relacionar ao máximo as políticas e a realidade nas instituições de ensino ${ }^{9}$.

Para as situações de inadequação das práticas pedagógicas, Sassaki ${ }^{10}$ enumera com o termo de barreiras qualitativas a inadequação das práticas pedagógicas e administrativas. Alguns princípios que devem ser considerados para a resolução dessa inadequação são: singularidade de cada aluno; múltiplos estímulos para trabalhar as múltiplas inteligências; diferentes formas de ensinar para cada aluno; diversas formas de avaliar as capacidades de cada aluno; e coerência entre todas as partes da escola, considerando professores, funcionários e instalações, todas as partes devendo atuar em prol da inclusão.

A participação das pessoas com deficiência parece diretamente relacionada a capacidade que as mesmas tem de se adaptar em ambientes não inclusivos (que apresentam dificuldades para o processo educacional). A contribuição que toda a comunidade acadêmica, desde os gestores, passando por professores e funcionários, até os alunos, com ou sem deficiência, pode dar a esse processo deve ser considerada, devendo pensar também no planejamento e execução de ações inclusivas, sendo essa uma tendência repetida na literatura ${ }^{11}$.

\section{Conclusão}

A partir das considerações feitas nesse trabalho, é possível notar que a inclusão do AcD dentro do ambiente universitário pode acontecer, mas é imperativo que haja a cooperação entre os setores da educação, política e gestão, atuando todos para que a inclusão seja cada vez mais uma realidade nas Universidades do Brasil. Além disso, é fundamental que seja realizada uma conscientização geral visando uma formação adequada, tanto dos alunos com deficiência, no que tange aos seus direitos e deveres institucionais, bem como dos demais alunos e funcionários das instituições de ensino superior, para que saibam a melhor forma de realizar a inclusão desses alunos dentro do contexto do ensino superior.

Também vale observar que os AcD são as figuras centrais desse processo, devendo ser partes integrantes, não apenas como beneficiados da inclusão, mas como agentes da inclusão, agindo de forma a lidar com as situações de dificuldades e impedimentos, e não permitindo que o seu acesso a qualquer ambiente, seja de ensino, seja no geral, seja negado por sua deficiência.

\section{Referências}

1. Brasil. Constituição da República Federativa do Brasil. 1988. Disponível em: http://bd.camara.gov.br/bd/bitstream/handle/b dcamara/15261/constituicao federal 35ed.pdf?s equence=9. Acesso em: 14/09/2016

2. Brasil. Ministério da Educação. Gabinete do Ministro. Aviso Circular no 277. Brasília, 1996. Disponível em: http://portal.mec.gov.br/seesp/arquivos/pdf/avi so277.pdf. Acesso em: 14/09/2016

3. Conselho Nacional de Educação. Resolução n. 2, de 11 de setembro de 2001, institui as Diretrizes Nacionais para a Educação Especial na Educação Básica. Brasília: CNE/CEB, 2001 a.

4. Brasil. Portaria no 3.284/2003. 2003. Disponível

em http://portal.mec.gov.br/sesu/arquivos/pdf/port 3284.pdf. Acesso em 10/09/2016.

5. Brasil. Decreto nำ.611/2011. 2011. Disponível

em http://www.planalto.gov.br/ccivil 03/ ato20112014/2011/decreto/d7611.htm. Acesso em 09/04/2017

6. Brasil. Política Nacional de Educação Especial na Perspectiva da Educação Inclusiva. 2008. Disponível em: http://portal.mec.gov.br/index.php?option=com docman\&view=download\&alias=16690-politicanacional-de-educacao-especial-na-perspectivada-educacao-inclusiva-05122014\&Itemid $=30192$. Acesso em 10/09/2016. 
7. Brasil. Lei no 13.146/2015. Lei Brasileira de Inclusão da Pessoa com Deficiência (Estatuto da Pessoa com Deficiência). 2015. Disponível em: http://www.planalto.gov.br/ccivil 03/ ato20152018/2015/lei/l13146.htm. Acesso em: 09/04/2017

8. Santos JB. Inclusão e preconceito na Universidade: Possibilidades e limites para estudantes com deficiência. IN: Miranda TG, Galvão Filho TA. (Org.) O professor e a educação inclusiva: formação, práticas e lugares. Salvador: EDUFBA, 2012, 491.

9. Duarte ER, Rafael, CBS, Filgueiras, JF, Neves, CM, Ferreira, MEC. Estudo de caso sobre a inclusão de alunos com deficiência no Ensino Superior. Revista Brasileira de Educação Especial, 2011, 19(2), 289-300. https://dx.doi.org/10.1590/S1413-

65382013000200011 . Acesso em 19/04/2017.

10. Sassaki RK.). Educação Inclusiva: barreiras e soluções. Incluir (São Paulo) 12, jul/ago 2011, p. 53. Disponível em: http://diversa.org.br/uploads/arquivos/artigos/a rtigo romeu dezembro vf.pdf. Acesso em 10/09/2016.

11. Calheiros DD, Fumes ND. A inclusão de universitários com deficiência em cursos de Educação Física na cidade de Maceió/AL Avaliação: Revista da Avaliação da Educação Superior (Campinas). 2016 Jul;21(2):523-40. http://www.scielo.br/pdf/aval/v21n2/1982-

5765-aval-21-02-00523.pdf. Acesso em: 04/04/2017.

\section{Endereço para Correspondência}

Universidade Estadual do Sudoeste da Bahia UESB

Av. José Moreira Sobrinho, s/n - Jequiezinho Jequié (BA)

CEP.: 45206-510

e-mail: rafaelspassos08@gmail.com

Recebido em 15/09/2016

Aprovado em 08/05/2017

Publicado em 11/05/2017 